\title{
Editorial: Emerging Issues Regarding the Intersection of Climate, Toxic Substances, and Environmental Health
}

\author{
Raul P. Lejano ${ }^{1 \star}$, Kyung-Min $\mathrm{Nam}^{2}$, Susanne Heise ${ }^{3}$ and Peter S. Hooda ${ }^{4}$ \\ ${ }^{1}$ Environmental Conservation Education Program, New York University, New York, NY, United States, ${ }^{2}$ Department of Urban \\ Planning and Design, The University of Hong Kong, Hong Kong, China, ${ }^{3}$ Faculty of Life Sciences, Hamburg University of Applied \\ Sciences, Hamburg, Germany, ${ }^{4}$ Department of Geography, Geology and the Environment, Kingston University London, Kingston \\ upon Thames, United Kingdom
}

Keywords: climate change, toxic pollutants, cap-and-trade, environmental health, environmental policy

Editorial on the Research Topic

Emerging Issues Regarding the Intersection of Climate, Toxic Substances, and Environmental Health

This is a year for re-assessment. As the world increasingly hopes to emerge from the grip of a pandemic, we consider where we are at and what's next. There are signs of hope on the environmental front, as the U.S. rejoins the Paris accord, and renewable energy emerges as one of the world's leading growth markets. There are worrying signs, however. The pandemic has furthered the rise of fundamentalisms and encroachment on human rights, which invariably also impacts collective values such as environmental and ecological health. Increased ideological conflict between nations threaten to hinder international cooperation. New areas of global inequity emerge, such as the access to vaccines of developing world nations. As the IPCC (Intergovernmental Panel on Climate Change) prepares its Sixth Assessment Report, this is the year to take stock, strategize, and reinvigorate our efforts to promote global health.

It is in this light that we call for a re-appraisal of where the climate and environmental health agendas are heading. We say "agendas," in the plural, because they are most often treated as separate thematic issues (often within the same journal). It is time to begin looking at intersectionalities, beginning with these two important issues. And, so, we present this special issue as a first step in bringing to the light new questions regarding the intersection of climate and environmental health.

These questions include:

1) What synergies, antagonisms, and other intersections can we find between the risks to societies and ecologies posed by climate change and by environmental pollution?

Received: 18 July 2021

Accepted: 28 July 2021

Published: 10 August 2021

Citation:

Lejano RP, Nam K-M, Heise S and Hooda PS (2021) Editorial: Emerging Issues Regarding the Intersection of

Climate, Toxic Substances, and

Environmental Health.

Front. Environ. Sci. 9:743267.

doi: 10.3389/fenvs.2021.743267

2) What synergies, antagonisms, and other intersections (between climate change and environmental health) can we find on the level of policy? What are the unrecognized cobenefits (and unintended negative externalities) associated with climate change mitigation and adaptation?

3) Are vulnerabilities heightened even further by intersectionality? Are those communities that are most vulnerable to health risks from toxics also those most burdened by climate risk?

The IPCC has begun considering some of these intersectionalities. For example, it devotes some space to the co-benefits of carbon and pollution control (IPCC, Intergovernmental Panel on Climate 
Change 2021). Clearly, there is ample reason to believe that the co-benefits in terms of human health alone are considerable (e.g., Markandya et al., 2018). However, the separation of policy domains suggests that there are overlapping synergies that are not being taken advantage of, and unanticipated harms that are being ignored. And this points to a need for further integration with other policy fields (e.g., urban planning, transportation, public health, social services, and others).

As focus on intersectionality means not treating the risks from climate change and toxics separately, so too does it suggest a need to stop formulating and analyzing policy responses to these two problems separately. In this issue, articles by Frogner-Kockum et al.; Materu et al.; Breedveld et al.; and Kim et al. address the issue of the effect of climate on the fate and transport of toxic pollutants. The articles by Wang et al. and Lejano et al. evaluate the impacts of climate mitigation policy, specifically, carbon emissions trading. Restrepo examines co-benefits in terms of criteria pollutant reductions with GHG-related controls on urban traffic.

\section{THE INTERSECTIONALITY OF RISK}

Several papers in this special issue investigate the connection between climate change and the fate and transport of potentially toxic pollutants. One mechanism is through extreme weather events that may increase in frequency and severity, and there is gathering evidence that, for example, this may be true in the case of tropical cyclones (e.g., Emanuel, 2021).

Breedveld et al. investigate the potential for increased toxics runoff during increased extreme weather events attendant to climate change. Measuring polycyclic aromatic hydrocarbons $(\mathrm{PAH})$, chlorinated paraffins $(\mathrm{CPF})$ and selected metals in sediments, they found a marked episodic response in contaminant load emitted from the river to a fjord in Oslo, Norway.

Similarly, Frogner-Kockum et al. correlated riverine loads of heavy metals and suspended solids with precipitation records dating back to 1961. They found a significant association between short-term increases in precipitation with particle bound metal transport in urban watercourses of the Göta Älv River in Gothenberg. They discuss implications of these patterns for changing meteorology due to climate change.

Materu et al. found a seasonal response in pesticide contamination in low-altitude freshwater wetland in East Africa. They found that pesticide transport from nearby sugarcane, teak and rice plantations resulted in significant ecological risk to aquatic and benthic organisms.

\section{THE CO-GENERATION OF BENEFITS AND HARMS}

Greenhouse gases (GHGs) are not conventional air pollutants, but combustion of fossil fuels simultaneously co-produces both
GHGs and conventional air pollutants, creating an interactive policy space (Nam et al., 2013). Climate-mitigation policies requiring improved energy efficiency and carbon intensity necessarily contribute to pollution abatement and, thus, from a regulatory perspective, emissions trading can be viewed as an indirect air-quality enhancer (Nam, 2016). In this special issue, the article by Wang et al. examines potential economic effects of China's national emissions trading scheme on achieving its pledged mitigation targets, focusing on the scheme's potential extension to include Hong Kong. The authors find that China's integrated carbon market enables Hong Kong to achieve the same reduction goal at up to $78 \%$ lower costs without significantly affecting the Mainland's economy, and demonstrate the economic rationale for cross-border cooperation in GHG regulations.

Reducing greenhouse gases can dovetail with already existing programs for local and regional air quality improvement. The potential for achieving co-benefits is appreciable, and one particularly impactful area of intervention is transportation. In this special issue, Restrepo examines reductions in street traffic in New York City, during the COVID-19 related shutdown, and its considerable effect on reducing ambient NO2. From this natural experiment, one can extrapolate the potential co-benefits to be realized with future interventions in the transportation sector to achieve GHG reduction targets.

However, there are inevitable externalities associated with the trade of carbon between emitters and between places, as discussed in the article by Lejano et al.. Their analysis illustrates how the exchange of carbon credits between refineries can increase the level of toxic emissions in local areas because, along with $\mathrm{CO}_{2}$ and other GHGs, refinery emissions will include appreciable amounts of toxic air pollutants which may surreptitiously increase in one area, unless particular attention is paid by the regulator to these.

\section{CONCLUSION}

Bourdieu once famously suggested that, as researchers, we might benefit much from examining not only the objects of our study but the spaces between them (Bourdieu, 1992). One such space is the intersection between climate change (and mitigation and adaptation activities related to it) and toxic pollutants. We identify a number of pertinent questions in this regard. The pieces found in this focused issue are merely a first step. They do not address all the issues broached above, and nothing conclusive can be said beyond these initial observations. Nevertheless, we see this as the start of an ongoing conversation, one that should lead to fruitful research in the years ahead.

\section{AUTHOR CONTRIBUTIONS}

All authors listed have made a substantial, direct, and intellectual contribution to the work and approved it for publication. 


\section{REFERENCES}

Bourdieu, P. (1992). “Thinking Relationally," in An Invitation to Reflexive Sociology. Editors P. Bourdieu and L. J. Wacquant (Chicago: University of Chicago Press), 224-234.

Emanuel, K. (2021). Response of Global Tropical Cyclone Activity to Increasing CO2: Results from Downscaling CMIP6 Models. J. Clim. 34 (1), 57-70. doi:10.1175/jcli-d-20-0367.1

IPCC, Intergovernmental Panel on Climate Change (2021). Sixth Assessment Report Fact Sheet. Availabla at: https://www.ipcc.ch/site/assets/uploads/2021/ 06/Fact_sheet_AR6.pdf (Accessed June 30, 2021).

Markandya, A., Sampedro, J., Smith, S. J., Van Dingenen, R., Pizarro-Irizar, C., Arto, I., et al. (2018). Health Co-benefits from Air Pollution and Mitigation Costs of the Paris Agreement: a Modelling Study. Lancet Planet. Health 2 (3), e126-e133. doi:10.1016/s2542-5196(18)30029-9

Nam, K.-M. (2016). "Need for Coordination between Greenhouse Gas and Pollution Abatement Regulations: China's Case and its Implications for Korea," in Quantitative Regional Economic and Environmental Analysis for Sustainability in Korea. Editors E. Kim and B. H. S. Kim (Singapore: Springer), 191-208. doi:10.1007/978-981-10-0300-4_11
Nam, K.-M., Waugh, C. J., Paltsev, S., Reilly, J. M., and Karplus, V. J. (2013). Carbon Co-benefits of Tighter SO2 and NOx Regulations in China. Glob. Environ. Change 23, 1648-1661. doi:10.1016/j.gloenvcha.2013.09.003

Conflict of Interest: The authors declare that the research was conducted in the absence of any commercial or financial relationships that could be construed as a potential conflict of interest.

Publisher's Note: All claims expressed in this article are solely those of the authors and do not necessarily represent those of their affiliated organizations, or those of the publisher, the editors and the reviewers. Any product that may be evaluated in this article, or claim that may be made by its manufacturer, is not guaranteed or endorsed by the publisher.

Copyright (c) 2021 Lejano, Nam, Heise and Hooda. This is an open-access article distributed under the terms of the Creative Commons Attribution License (CC BY). The use, distribution or reproduction in other forums is permitted, provided the original author(s) and the copyright owner(s) are credited and that the original publication in this journal is cited, in accordance with accepted academic practice. No use, distribution or reproduction is permitted which does not comply with these terms. 